\title{
Papillary Dermis
}

National Cancer Institute

\section{Source}

National Cancer Institute. Papillary Dermis. NCI Thesaurus. Code C94819.

The upper portion of the dermis beneath the epidermis. It is composed of thin collagen fibers. 